\title{
Gaining ground: An exploration into the lives of Missouri's lesbian farmers
}

\author{
Sarah E. Cramer* \\ Stetson University
}

Submitted August 1, 2019 / Revised October 24 and November 14, 2019 / Accepted November 14, 2019 /

Published online April 24, 2020

Citation: Cramer, S. E. (2020). Gaining ground: An exploration into the lives of Missouri's

lesbian farmers. Journal of Agriculture, Food Systems, and Community Development, 9(3), 163-178.

https://doi.org/10.5304/jafscd.2020.093.017

Copyright (C) 2020 by the Author. Published by the Lyson Center for Civic Agriculture and Food Systems. Open access under CC-BY license.

\begin{abstract}
Formerly "invisible," lesbian farmers have received increased attention recently, within both sociological scholarship and the popular media. Despite this attention, preconceptions about their lives persist. Assumptions of gay culture existing exclusively in metropolitan areas and of rural culture remaining organized by blood linkage and land ownership, combined with the continued predominance of men in agriculture, make this evolving realm of inquiry relevant to social scientists, agriculturalists, and extension professionals. In light of these intersections of identities and assumptions, and the remaining gaps in scholarship concerning this population, I conducted a case study, which was situated within a framework of ecogender studies. As such, the research focused on gendered relationships with nature and the emancipatory potential of women reclaiming their connections to
\end{abstract}

** Sarah E. Cramer, Department of Environmental Science and Studies, Stetson University; DeLand, Florida, USA; scramer@stetson.edu nature through agriculture. The experiences of this population provide transferable lessons about humans as food system participants and present opportunities for rural development through sustainable agriculture.

\section{Keywords}

Lesbian, Sustainable Agriculture, Ecofeminism, Ecogender Studies, Community Development, Queer Farmers, Food Systems

\section{Introduction}

An investigation into the lives of lesbian farmers in the United States, within Missouri specifically, engages with multifaceted notions of identity, culture, and geography. Missouri is a conservative state dominated by a conventional agriculture, and its resident lesbian farmers must navigate challenging economic, political, and social landscapes. While relevant academic disciplines, such as rural sociol-

\section{Disclosure}

This research received IRB approval. 
ogy or queer studies, are evolving, scholarship is often still characterized by assumptions into which lesbian farmers do not fit. Assumptions of gay culture existing exclusively in metropolitan areas and of rural culture remaining organized by blood linkage and land ownership (Bell \& Valentine, 1995; Oswald \& Culton, 2003), combined with the continued predominance of men in agriculture (U.S. Department of Agriculture [USDA], 2012), make it difficult to situate a study of lesbian farmers into a prescribed framework. Even as queer farmers gain modest attention in the media, gay men and lesbian women remain grouped together, although the experiences of gay men and lesbian women in agriculture often are vastly different (Kazyak, 2012). As Carolyn Sachs states, "Lesbians in rural places remain invisible to scholars, to other rural people, and to the urban gay and lesbian culture" (Sachs, 1996, p. 24). Though lesbian farmers' experiences may overlap with those of other women-identifying farmers, assuming a universalism in experience among female farmers contributes to a further erasure of lesbian women. Sexuality has become an important part of the intersectionality discussion that was previously limited to race, class, and gender, and this research was intended to contribute to that conversation in the context of Missouri's agriculture and food systems (Taylor, Hines, \& Casey, 2010).

As the queer community continues to experience greater acceptance and acknowledgment on a national and regional scale, its members still encounter prejudice, especially in a conservative region like the rural Midwest. For example, the Missouri Farm Bureau (MFB), which claims to be the "state's most effective organization working to improve the quality of life for farmers, rural Missouri, and all Missourians" (MFB, n.d., "What we're all about," para. 1), still included statements in their yearly policy handbook such as, "We are opposed to the legalization of gay marriages by either state or national legislation" and "We oppose the concept of a 'Gay Bill of Rights"' (MFB, 2020, p. 91), years after Obergefell $v$. Hodges (2015) and the Supreme Court's recognition of marriage equality. The bulk of this research preceded both the infamous Rush Limbaugh comments about lesbian farmers (Limbaugh, 2016) and the 2016 presiden- tial election, and since then, the intersections of rural social dynamics, gender politics, and environmental and agricultural concerns have only become more tense and fraught with anxiety. Many are asking what the future of rural America will look like, who will be welcome, and how they will make a living there. This study endeavored to examine those questions from the standpoint of a particular population.

The main driving question behind this study was: What are the lived experiences of Missouri's lesbian farmers? From this central issue question flowed additional subquestions related to how gender influences and engages with agricultural production, and how a rural, conservative setting constrains or shapes the lives of lesbian women. In this paper, I argue that it is sexuality and/or gender expression, and not just gender, that affects Missouri women's experiences in agriculture. Additionally, I argue that research, sustainable agriculture advocacy, agricultural extension work, and rural development initiatives must attend to sexuality in intersection with gender. The women whose stories appear in this work have planted seeds of alternative ways to engage with agriculture and the environment, and they are forging a path for a sustainable agriculture through the monocultural corn and soy fields of Missouri.

\section{Review of Literature}

Most relevant literature stems from broader categories of sociological research in either rural queer studies or on women farmers. It is important to recognize the distinctions between these areas of literature, as, historically, rural queer studies work rarely differentiated between the needs or experiences of gay men and lesbian women, and women's studies work rarely differentiated between straight and lesbian women. This review will lay a foundation for the study based upon feminist scholarship of food and agriculture, relevant concepts from rural queer studies literature, and a discussion of "landdykes," female masculinity, and additional notions pertaining specifically to the lives of lesbian farmers.

In recent decades, scholars have applied feminist lenses to studies of agriculture and environmental sustainability and have examined how 
various interpretations and demonstrations of masculinities can be seen in American agriculture (Ferrell, 2012; Peter, Bell, Jarganin, \& Bauer, 2000). A popular example of the linkages between the technology-dependent, conventional agriculture of the United States and masculinity is the symbolism of the tractor (Barlett \& Conger, 2004; Brandth, 1995). Tangibly, the ability to operate large machinery, like a tractor, requires skills often demarcated along gender lines. Even women who grew up on farms, and especially those with brothers or close male relatives, may not have been trained in tractor work. The tractor clearly separates men's labor on a farm from women's labor. Symbolically, the tractor represents the strength, efficiency, and dominance over nature expected of traditional male farmers.

Despite the gendered symbolism, both men and women may enact masculine or feminine approaches to agriculture (Peter et al., 2000). Sustainable agriculture, in its various forms, is often described as a more nurturing or feminine approach to agriculture, and without ascribing gendered essentialism to the work, women farmers are, for example, more likely to farm organically (Rissing, 2013; USDA National Agricultural Statistics Service [USDA NASS], 2014b). Trauger (2004) has argued that while traditional models of agricultural production may prevent women from independently acquiring capital, alienate them from knowledge and support, and relegate them to the role of "farm wife," the sustainable agriculture movement has empowered women and created space for them to cultivate identities as farmers. The feminist agrifood systems theory (FAST) expands Trauger's argument further and articulates the following six themes pertaining to women farmers in sustainable agriculture (Sachs, Barbercheck, Brasier, Kiernan, \& Terman, 2016, p. 2), asserting that women farmers:

1. create gender equality on farms amid broad societal changes in gender roles,

2. assert the identity of farmer,

3. access the resources they need to farm by pursuing innovative ways to access land, labor, and capital,

4. shape new food and farming systems by in- tegrating economic, environmental, and social values,

5. negotiate their roles in agricultural organizations and institutions, and

6. form new networking organizations for women farmers.

Although FAST, and its supporting scholarship, mark a recognition of the formerly hidden lives of women farmers, it still falls short of encompassing a fully intersectional view of farmer identities and gives no attention to the lives of lesbian farmers. This is ironic given that Sachs first coined the term "invisible farmer" to describe the hidden contributions of women on farms (1983). While there has been an increase in women principal operators on United States farms in recent years, up to $14 \%$ between the 2007 and 2012 agricultural censuses (USDA National Agricultural Statistics Service [USDA NASS], 2014a), research has created a new iteration of invisible farmers in ignoring the experiences of lesbian farmers. This is an example of the heterosexism that persists within the sustainable agriculture movement (Leslie, 2017). While sustainable agriculture is often considered a more progressive and equitable space in the larger landscape of American agriculture, it is still bound by many heterosexist norms. Leslie described the persistence of the family farm as the primary business model in sustainable agriculture as an example of a heterosexist institution, and he discussed how queer farmers are often pressured to reproduce this model to remain viable. He argued for a broader "queering" of food systems that only considers agriculture sustainable when the diverse relationships and livelihoods of its actors are sustainable as well. Wypler (2019) built upon this call in her work examining lesbian and queer sustainable farmer networks in the Midwest. She argued that traditional, heteropatriarchal forms of farmer support do not align with queer farmers' agricultural practices or queer identities, and that queer farmers must build networks outside of these conventional avenues in order to be truly sustainable.

Because the literature on women farmers leaves the aforementioned heterosexist gaps, related literature on the identities of rural, nonfarmer, lesbian women helps construct a more complete 
impression of the lives of lesbian farmers. The concept of rural gender presentation as "female masculinity" is one theme that emerges from the literature, as discussed extensively by Emily Kazyak (2012). She stated, "Masculine gender practices, from wearing flannel shirts to working in traditionally male-dominated jobs, are part of how the category 'lesbian' is constructed" (Kazyak, 2012, p. 824). She also addressed the notion that although traditional femininity in rural cultures is synonymous with heterosexuality, rural areas are not necessarily inclined to stigmatize female masculinity. Whereas a more masculine appearance may signify lesbian sexuality in urban environments, the lines between feminine and masculine in terms of dress and labor are often blurred in rural society, where straight women may also engage in farm work and dress accordingly. To Kazyak's interpretation, this acceptance of a more masculine gender presentation among rural women may contribute to the creation of a more welcoming space for lesbian farmers in the rural Midwest. Importantly, this work provides an example of the distinct differences between gay men and lesbian women's experiences in rural society, as "male femininity" is not nearly as well accepted (Fellows, 1998). Though these scholars certainly do not assert that all lesbians are "butch" or that all gay men are "femme," their work speaks to a flexibility in rural gender presentation norms that may be advantageous for lesbian farmers. These diverse and fluid concepts of gender presentation, and how they challenge cultural norms in rural society, serve as a reminder of the value of examining distinct queer populations individually.

Kazyak (2011) also examined the geographic elements that contribute to the construction of rural queer identities. Although common cultural narratives paint the rural Midwest as a place where "gay and lesbian sexualities are unclaimed, stunted, or destroyed" (Kazyak, 2011, p. 561), she argued that rural gay and lesbian individuals actively modify cultural narratives to develop their own rural queer identities that are unlinked from, and often opposed to, those of urban queer communities. Individuals construct identities around "being known as a good person" and having long-standing ties in their rural communities (Kazyak, 2011, p. 571).
Kazyak discussed a seemingly counterintuitive trend of queer individuals fleeing from urban areas to rural areas as part of the process of coming out, while acknowledging the social isolation that still affects the lives of rural gay and lesbian residents. Her work contributes to the ongoing disentangling of queer culture from urban culture and presents processes of queer identity construction that are uniquely rural (Gray, Johnson, \& Gilley, 2016).

Another main theme from the literature is that of lesbian community building in rural society. First, as Bell and Valentine (1995) explained, it is important to differentiate between queer individuals who are born in rural locations and those who choose to relocate to the country. Intentional decisions to locate to rural areas represent a form of rural queer identity construction, as outlined by Kazyak (2011), but also represent a privilege and an agency that may not exist for all rural-born queer individuals. The lesbian land movement in the U.S. is an example of this trend of rural relocation and dates back to the 1970s, during which numerous lesbians founded a network of women-only farms and developed a society free from men (Anahita, 2003). Members of this original movement were unified in their adherence to ecologically sustainable practices, self-sufficiency, and a belief in radical lesbian feminism, and endeavored to build resilient communities that aligned with those principles (Anahita, 2009). It is estimated that currently more than 200 of these communities, now known as "landdyke communities," remain scattered throughout rural America (Anahita, 2003). A modern manifestation of the movement's ideals can be seen, for example, in the work of the Lesbian Natural Resources organization (LNR, n.d.).

Lesbian farmers may be motivated to pursue agriculture for myriad reasons. As women, they may be drawn to sustainable agriculture as a space that is affirming of their identities as farmers (Sachs et al., 2016). Rural environments may be more inviting for women who construct an identity of female masculinity and hope to dress and behave accordingly (Kazyak, 2012). Across these bodies of literature, there are threads of autonomy, community-building, and a desire to work in concert with nature. It was the intention for this study to provide a snapshot of Missouri's lesbian farmers that 
continues to draw together the work that has been done on gender and agriculture and recent work on queerness in agriculture, and in doing so to examine the opportunities and implications for rural life, agriculture, and the environment.

\section{Ecofeminist Roots and an Ecogender Studies Framework}

Ecofeminist theories first emerged in the 1980s as an extension of both the environmental and women's movements (Salleh, 1984). In its earliest form, ecofeminism was simply the acknowledgment of the parallel and similar dominations of both women and nature by men. As the theory expanded and evolved over time, it influenced a wide array of environmental and feminist movements and corresponding scholarship (Warren, 1996). Although its myriad tenets continue to be redefined, at its core, ecofeminist theory asserts that human interactions with nature are inherently gendered and that the reclaiming of women's connections to nature has emancipatory potential for both women and nature.

Only in select instances has an ecofeminist lens been applied to agricultural contexts. The use of this highly critical framework has shed new light on the environmental and social issues within conventional agriculture and contributed an additional argument for sustainable agriculture (Sachs, 1992). Sachs asserted that agricultural social science must consider four levels of diversity, or lack thereof, in the agricultural system: biological, cultural, structural, and product. She encouraged scholars to attend to cultural diversity in their discussions of agricultural biodiversity and theorized connections between human diversity and agricultural sustainability and diversity. Given the philosophical underpinnings of this application of ecofeminist theory, as well as the claim (substantiated by literature) that women play key roles within the sustainable agriculture movement, ecofeminist thinking laid an initial theoretical foundation of this study (Gershuny, 1991; Jarosz, 2011).

Banerjee and Bell (2007) synthesized decades of debate surrounding ecofeminist social science and feminist political ecology into a single framework for social science research entitled "ecogender studies." While the authors provided a clear structure for the framework's use by outlining tenets and methodological positions, which are addressed below, what makes the framework of ecogender studies particularly valuable is its acknowledgment of the issues of previous ecofeminist scholarship, such as romanticization of women's work.

Banerjee and Bell expanded the lines of ecofeminist inquiry by conceptualizing the diversity of experiences of both women and men, and recognizing that complete emancipation of women, or any other oppressed group, can only occur through the elimination of ideological and material domination of women, men, and the natural world.

Ecogender studies acknowledges that relationships between men and women, between individuals and the larger society, and between humans and nature are unfathomably complex and deeply rooted in historical structures of oppression. The work of transformation of these relationships and emancipation of the involved parties cannot occur in isolation or in a state of ignorance of these historical contexts.

Finally, Banerjee and Bell outlined four central methodological principles that guided this study: locationality and reflexivity, dialogics and relationality, critical and interrogable, and multiple methods and triangulation. The structural impacts of these influences on the research methods will be explored further in the following sections, but Banerjee and Bell's work urged me to examine and triangulate my findings from as many directions as possible, to branch out into novel and experimental sources of data, and to explore the lives of Missouri's lesbian farmers in ways that fostered an emergent analysis that was critical, dialogic, and relational.

\section{Research Methods}

\section{Qualitative Case Study}

The research employed a qualitative case study design (Stake, 1995). Because case study research is framed around an understanding of the bounded system, case study researchers articulate inclusion criteria in terms of elements that fall within the boundaries and those that do not (Yin, 2003). All participants in this study were self-identified, cis- 
gendered, lesbian women. All participants were farming full time at the time of the study as a farm employee, farm owner, and/or principal operator. Participants lived and farmed in Missouri at the time of the study. An understanding of the lived experiences of Missouri's lesbian farmers cannot be extrapolated to constitute an understanding of the lived experiences of lesbian or queer farmers nationally or globally, although transferable lessons exist. I acknowledge that while the tight bounds of the study excluded other queer women-identifying individuals, they may see their experiences reflected in the data as well. Additionally, I acknowledge that the labels we use to describe gender and sexuality are rapidly evolving, and the terms used in this paper reflect a particular moment in time and the preferences of a particular set of participants.

\section{Missouri as Place}

The context of the study, Missouri, shaped the phenomenon under scrutiny. Cultural geographer J. B. Jackson famously stated, "It is place, permanent position both in the social and topographical sense, that gives us our identity" (Jackson, 1984, p. 152). In both explicit and implicit ways, Missouri, as place, shaped the identity development of the research participants, as well as their livelihoods and community support systems. Additionally, in a case study inquiry, researchers acknowledge the inextricable connections between research phenomena and setting (Stake, 1995; Yin, 2003).

Missouri sits in the center of the continental United States, bordered to the east by the Mississippi River and bisected latitudinally by the Missouri River. As of the 2010 Census, $70 \%$ of Missouri's 6 million residents lived in urban areas, although roughly $97 \%$ of the land area of the state was classified as rural (U.S. Department of Commerce [USDC], 2012). At the time of this writing, Missouri ranked second among the 50 states in number of farms with 99,170; only 175 of those farms were certified organic. The state's top five agricultural commodities are soybeans, corn, cattle and calves, hogs, and broilers, although the diversity of terrain across the state supports regionally specific crops such as wine grapes and elderberries along the major rivers and rice in the "Bootheel" of the southeast corner (USDA, 2018). The major engine of agricultural research is the land-grant institution, the University of Missouri, whose College of Agriculture, Food, and Natural Resources (CAFNR) manages more than 14,000 acres $(5,700$ hectares) of research plots across the state, and whose cooperative extension disseminates research findings to Missouri farmers (CAFNR, n.d.). Specialty crop and small-scale agricultural research and extension are primarily handled by Lincoln University, the 1890, historically black land-grant institution. As a final note about the significance of place in this research, it is worth remembering that the Monsanto Company (now owned by Bayer) is located in St. Louis, Missouri, and that its influence on the state's agriculture industry cannot be overstated.

\section{Data Sources and Iterative Analysis}

A feature of case study research that also aligns neatly within the ecogender studies framework is the use of multiple data sources to facilitate triangulation (Banerjee \& Bell, 2007; Stake, 1995). Unlike many traditional qualitative studies, which emphasize participant interviews as the primary data source (Creswell, 2013), for this study, only two formal participant interviews were conducted. This elimination of data hierarchies in favor of a more holistic, immersive approach to data collection and analysis is a response to Banerjee and Bell (2007). While researchers often describe data sources as "primary" or "secondary," in this work I reject the masculine acts of categorization and ranking of data and present the discussion of sources more generally.

The ongoing, iterative process of qualitative data collection and analysis in this study began with the accumulation and analysis of electronic artifacts in the vein of a traditional document analysis (Bowen, 2009). To begin, I conducted keyword searches on Instagram using various hashtags such as \#queerfarmers (which yielded 2,369 posts), \#farmher (108,561 posts), and \#queerswhofarm (718 posts). Interestingly, the hashtag \#landdyke only yielded five posts at the time of data collection, which may speak to a generational division (women who identify as landdykes may not be women who utilize Instagram). In a way, this process of data collection constituted a virtual method 
of snowball sampling (Browne, 2005), because with each click on a hashtag I was led to posts with different, but tangentially related keywords I had not thought to search for before, such as \#ruralqueers or \#countryqueers. It is fitting to frame this as virtual snowball sampling, because following these hashtag trails provided insight into relatively concealed virtual populations, just as snowball sampling of participants provides entrée into populations that are hidden from the world in some way.

The Instagram posts served as a first step into the electronic document analysis component of the research. All posts were not critically analyzed, as most of them did not fall within the bounded system of the case study (Missouri, lesbian, farmer/agriculture). Most posts represented a context other than Missouri, as identified by Instagram's location tagging, and the term "queer" is far more inclusive than "lesbian," so many posts represented individuals who did not meet the inclusion criteria of the case. A final purposive sample of 50 appropriate images was analyzed using a framework for visual content analysis, which drew from Highfield and Leaver (2015) and Hochman and Manovich (2013). A limitation of this data source is that lesbian farmers may not use Instagram personally or professionally, or if they do, they may choose not to tag their photos with the listed hashtags. Acknowledging the limitations of these data, they nevertheless contributed to the substantiation of themes from analysis of interview, observational, and additional artifact sources.

The next layer of electronic data came from a sample of 10 websites of lesbian-owned and/or operated farms in Missouri or bordering states. The boundary for this sample was expanded slightly due to the small number of websites of appropriate farms in Missouri alone. Websites were selected based upon either my previous knowledge of or engagement with the farm, or they were found through the Instagram keyword search process described above. I verified that the farmers identified as "lesbian," as opposed to "pan-" or "bisexual," by either direct member checking (asking the farmers themselves), confirming the use of the term in their online presence (website or Instagram feed), or as part of the snowball sampling process (asking self-identified lesbian farmers to point me towards other lesbian farmers). The textual content of the websites, with a specific focus on the "About" page or homepage of each site, was copied and analyzed line-by-line to begin the focused process of theme development (Bowen, 2009). Although this analysis preceded much of the remaining data collection, as an iterative process, I returned to these websites and photographs repeatedly over the course of the study to re-ground myself in the case and triangulate findings.

Unstructured interactive interviews (Corbin \& Morse, 2003) and observation constituted additional sources of data, which were collected over a two-year period. In total, I engaged in conversational data collection with 10 of Missouri's lesbian farmers and conducted approximately 60 hours of observational data collection. Sites of observation included participants' farms during their routine workdays, relevant agricultural production conferences, and queer farmer social events. A reflexive journal of notes constitutes the audit trail of this data collection process (Creswell, 2013). Finally, two archetypal lesbian farmers in Missouri were formally interviewed to further substantiate emergent themes and gather representative quotes to pair with the themes. These 90-minute, semistructured interviews were conducted on each farmer's respective farm and were fully transcribed and coded. Both women were identified through my networks within the Missouri agriculture and queer communities, and purposively selected based on their diverse experiences within and knowledge of Missouri agriculture. Their embeddedness in the social and agricultural landscape of the region lends additional depth to their contributions to the research. Participants are assigned pseudonyms in the findings.

\section{Researcher Reflexivity}

An acknowledgment of the researcher's positionality and biases is necessary in qualitative research, as the researcher serves as the primary research instrument (Creswell, 2013). This disclosure is additionally important in case study research, which is often accused of fostering verification bias and confirming the researcher's preconceived notions about the study topic (Yin, 2003). At the time of 
the research, I was embedded in the local sustainable agriculture community. I am a queer woman, and I was the sole instrument of data collection and analysis. My family has farmed in Missouri for six generations, and I have a deep connection to the state and affinity for its history, landscape, agriculture, and communities. I have an unquestionable personal bias in developing and conducting the study, and took care to bracket out my own opinions and experiences throughout data collection and diligently engage in reflexive journaling to examine and question my positionality and limit my influence on the data. While bias stemming from my personal standpoint is unavoidable, my position within the bounded system granted valuable entrée into the research population and insight into the subtleties of their lived experiences.

\section{Trustworthiness}

Qualitative researchers grapple with establishing and expressing the validity of their findings (Creswell \& Miller, 2000), especially when working across disciplines or combining social and natural sciences (Rust et al., 2017). I worked to establish trustworthiness throughout the process, specifically the credibility, dependability, and confirmability of the work (Lincoln \& Guba, 1985). I engaged in ongoing member checks in which I shared data and its interpretation, as well as the final manuscript, with participants to ensure that the research findings appropriately represented their experiences (Creswell, 2013). The case study was conducted within a tightly bounded system, so I make no claims of generalizability of the work, although transferable lessons may be drawn from the findings to other relevant contexts. I acknowledge that there may be other interpretations of the data. Data collection was continued until a complete understanding of the participants' perspectives was reached. Given the data sources and methods of this research, the "complete understanding" was achieved when Instagram and website artifacts, as well as observation and interview data, became redundant.

\section{Findings}

From the analysis of the semistructured and unstructured interviews, electronic artifact data, ob- servational data, and reflexive journals, five clear themes emerged: Building community, working relationship with men in agriculture, female masculinity, proving yourself, and conservative surroundings. Below are the descriptions of each theme, representative examples or quotes, and any corresponding subcategories.

\section{A Note About Sustainability}

Although it was not a criterion for inclusion, all lesbian-owned or -operated farms included in the research were small (under 10 acres or 4 hectares in production), diverse, and "sustainable" (described by participants in myriad ways, including certified organic, not certified but utilizing organic practices, ecological, no-till, or holistically managed). Farmers engaged in community supported agriculture, market farming, and restaurant sales. Participants would frequently position themselves within a paradigm of sustainability, and then contrast that with the paradigm of their surroundings. In the electronic artifacts, a commitment to sustainable agriculture was proudly highlighted and utilized to market farm products to interested consumers. Literature has explored connections between women farmers, queer farmers, and sustainable agriculture, so this trend was not surprising. Rather than pull this out as a discrete theme, when reading the findings below, it is useful to keep the overarching context of sustainability in mind. Retaining sustainability and cooperation with nature as an overarching context also serves to place each of the five discrete themes within the ecogender studies framework of the research.

\section{Building Community}

The topic of community, and the importance of building community, was omnipresent throughout data collection and findings development. This theme may be broken down into two similar but distinct subcategories: community supported agriculture and community support as a lesbian. These separate yet parallel concepts of community speak to the types of agriculture and the particular agricultural lifestyles to which Missouri's lesbian farmers were drawn.

Community supported agriculture (CSA), the more clearly defined and professionally relevant 
concept of the two, featured prominently throughout the electronic artifacts, with most farmers highlighting their CSA model on their websites. Both semistructured interview participants participated in the CSA model of farming. Jill talked about deciding to become a farmer after joining a CSA, stating, "I had no idea that people did this for a living. I had no idea that there was the potential for a community to be built around food production." This comment, which Jill often reiterates whenever she is asked about her operation, reflects the philosophy many participants held about the CSA model. Though it is possible to participate in a CSA in a purely transactional way, the participants, and their followings of customers, prioritized the community element, as illustrated by CSA member potlucks, frequent member workdays, and members-only farm parties.

In addition to the "community" in the CSA model, participants shared stories of the community built around the farmers market through regular interactions with customers, exchanging of recipes, and so forth. These linkages were clearly visible during observational data collection at open farm workdays. In these connections, the focal points of the community support were the food the farmer was growing or the land they were cultivating. Community members supported the women's lesbian identities by default, because CSA members, volunteers, or market shoppers supported the lesbian farmer as a steward of an agricultural system in which the consumer believed.

The subcategory of community support as a lesbian took a different form for each participant. Jill, who lived in an isolated, rural location, shared many stories of the male "gatekeeper" who helped her integrate into the community when she first arrived. She described the development of her "very dear, deep friendship with him," and that it "paved the way" in the community. She stated, "he won't let anybody say anything bad about me. Doesn't matter that I'm a lesbian, doesn't matter that I'm a woman." Finally, she said:

People in the country are so willing to help you if you need anything, but you have to be willing to try to become somehow part of the community. So if you as a farmer, lesbian, whatever, if you cannot figure out a way to get into the community and make yourself not so much of an outsider, then your life is gonna be tough.

Jill derived community support from her rural Missouri neighbors, but was able to provide support and serve as a mentor for young lesbian farmers who found their way to her farm in droves. In contrast, Laurie spoke more extensively about the notion of finding the support of the lesbian community within agriculture. She said that when she began farming, "it was pretty apparent that there are lots of lesbians in this career." She described her first farm internship, at a farm with an all-female staff and a lesbian director, as overwhelmingly positive, stating, "all of us, all women, working together made my introduction a lot easier than if I had gone to a place where it was all men and I felt inferior the whole time." Several participants shared this experience of seeking out lesbian mentorship on the farm. Women spoke of finding farming shortly after coming out as lesbian, and of feeling safe on the farm when they did not elsewhere.

Laurie had farmed in rural and urban environments throughout Missouri and had encountered supportive lesbian farmers in each location. Formerly, she had co-owned and operated an organic vegetable farm with her then-partner, a fellow lesbian farmer, for three years. They developed deep connections with an older lesbian landowner down the road from their farm. Laurie said, "we hung out with her a good amount. She had some friends, older lesbians, who would come over and we would have dinner. We got to know them pretty well, and that was kind of our community for those years." These lesbian community connections transcended rural and urban divides, but again retained the physical farm, or at least the realm of agricultural production, as the central context.

\section{Working Relationship with Men in Agriculture}

Participants extensively discussed their varied perspectives on working with men while farming. Some women found positive experiences of welcoming mentorship from straight male farmers, some experienced extensive negative interactions 
with men, and others worked to avoid men altogether, gravitating towards women-run farms reminiscent of the radical lesbian feminism of the landdykes.

As alluded to in the previous category, Jill's positive working relationships with men were typified by the older neighbor who helped her integrate into her rural community. In addition to helping her in that way, this particular friend regularly visited her farm to assist with farm chores. She said, "I found him, and he's been a farmer his whole life!" and said that although he was in his seventies, he came to the farm nearly every day to help out. She said, "I stock up in my mind, in my list of things to do, which is very long all the time, anything that has to do with a tractor because I know he's gonna show up sometime and need something to do." Jill also reflected on a male farmer mentor for whom she had worked very early in her farming career, stating, "I loved working for him, but I realized when I was working for him that I wanted to own my own farm." Jill acknowledged that while her experiences working with and for men in agriculture had been overwhelmingly positive, she understood that they were "probably very, very different" from those of other women she knew working in agriculture, and she remarked that she "has been severely lucky."

While Jill had been "severely lucky" in her working relationships with men, Laurie had not. After a series of apprenticeships, she and her former partner entered into an unconventional business relationship with an older male landowner in Missouri. While he retained ownership of the land, the two women co-owned the organic farm business and facilitated all of the farm operations (CSA operation, market sales, and direct-to-restaurant sales). While the women were in the partnership because they needed land but wanted to run things themselves, Laurie believed that what the landowner wanted from the partnership was the ability to be a mentor. She perceived heavily gendered overtones to the dynamics of this relationship. She said, "In terms of being a woman, there were definitely things that he thought we couldn't do on the farm that we really could." Over time the relationship became quite strained, especially as the farm business became successful. Laurie reflected:
He might say something totally different, but I felt like he wanted to bring us in so he could teach us things and he could get credit for teaching us things, and when he realized that we didn't need to be taught, and that actually we were really successful without him, he didn't like that so much.

I observed many of these contradictory working relationships with men throughout data collection, and they were often complicated by other factors such as age or race of either the men or the lesbian farmer participants. Older men would often "mansplain" farm tasks to the participants without first asking whether the women already knew what they were doing. While some women ignored the instructions of men, or reclaimed control of the situation and established their authority as a farmer, others carefully negotiated these interactions so as to avoid seeming "aggressive." Cautious negotiation was observed most frequently when the man involved in the interaction held a position of power over the woman and the woman did not want to offend him. Additionally, men with whom the women worked seemed to push professional boundaries with the participants and remark to them about the "hotness" of other female farm employees or made other similarly inappropriate statements.

\section{Female Masculinity}

This theme addresses concepts of gender presentation and identity among participants. Laurie reflected on her own relatively masculine gender presentation, and tied it to her observations about the prominence of lesbian women in agriculture, stating:

I think farming is considered more masculine, and you have to have some characteristics that aren't particularly girly. Like being strong and being dirty, and recognizing that my hands have callouses, and my nails are short because if I had long nails I'd have dirt under them all the time. So these kinds of characteristics tend to be more attractive to lesbians who feel like they have a little bit more masculinity in them. 
She also said, "I was definitely a tomboy, and still am, probably." Additionally, Laurie described what she perceived to be a special intersection of female masculinity, lesbianism, and market farming. She shared,

I think that as a lesbian who kind of embodies some of these masculine qualities, being strong and kind of burly, calloused and dirty, but also being a woman that appreciates and respects and wants to nurture the land, [market vegetable farming] is kind of the best of both worlds in that way. You're farming but you're also doing something that is nurturing.

Notions of gender presentation revealed themselves during observational data collection and electronic artifact analysis. Superficially, the lesbian farmers I observed generally wore stereotypically masculine clothing while farming, such as Carhartt pants and overalls, flannel shirts, and sturdy boots. Oftentimes these women were dressed more practically and masculinely than self-identified straight women coworkers, who were seen wearing shorts, tank tops, or sandals (and on one farm, were regularly scolded for the impracticality and inappropriateness of such clothing). The websites of lesbianowned and/or -operated farms, if they featured photos of the farmers themselves, showed the women engaged in farm work, dressed accordingly, or holding bountiful harvests of produce. These official, business-oriented sites were not used as platforms to challenge gender stereotypes but to advertise the farm. An exception to this was a flower farmer couple's website that advertised their services for all weddings by highlighting their involvement in the legal case that successfully challenged Missouri's gay marriage ban. Still, photos were often of flowers, children, and livestockimages that conveyed an impression of a feminine, nurturing approach to agriculture, rather than one of dominion. These images contrasted with those on Instagram, arguably a more youthful and boundary-pushing platform than professional websites, which displayed intentional "queering" of agriculture and expectations of gender presentation. For example, one image featured long, painted fingernails digging in the dirt and was tagged \#fiercefemme, while another showed a farmer with short hair, a large bouquet of flowers, and a shirt that read "get dirty." Although the theme of female masculinity remains salient, these contrasting instances illustrate the fluidity of gender expression and complicate a rigid stereotype that automatically equates masculinity with lesbianism or femininity with straightness.

\section{Proving Yourself}

Participants consistently reflected upon the importance of "proving themselves" in agriculture as a male-dominated industry. A narrative repeatedly emerged that differences in gender, sexuality, farm background, or age were secondary, and that the primary motivation in the participant's work life was to become a good farmer and prove to the world that she was competent. Laurie explicitly stated:

I feel like just being a woman in agriculture in this part of the country is rare and different and I find myself having to prove myself to lots of the men around me because they're older, they're white, they've grown up on farms or been around farms for a long time. I never want to come off as a prissy girl who doesn't know how to operate machinery or lift something. I never want them to feel like they have to say, "oh, let me do that for you, miss."

Laurie's discussion of needing to show that she was competent intersects clearly with conversations about negative and positive working relationships with men and the ensuing "mansplaining" that occurred during those interactions. Laurie's professional dynamic with men diverged from that of her straight female coworkers, who often asked for men to come complete a task on the farm. For a time, Laurie worked for a straight female supervisor, who made comments about leaving certain tasks, such as maintenance of machinery or heavy lifting "for the boys to take care of." These requests, laden with traditional gender roles and expectations, caused significant tension between Laurie and the supervisor, a tension which, when examined in light of Laurie's need to prove herself as a farmer, is not surprising. 
Like Laurie, Jill described how proving yourself as a competent farmer was the most important way to gain acceptance as lesbians and women in the Missouri agricultural community. Jill presented an excellent illustration of the value of the common ground of being a good farmer superseding other differences by sharing a story of a friend overhearing a conversation about her at a restaurant in a nearby town:

He was just sitting at a table having a cup of coffee and there were two old dudes sitting at the table right next to him, and, he hears one of them say "did you hear?" and my friend, he's so hilarious, he's playing this crazy accent and says, "did you hear that those two lesbians down at [farm], did you hear that one of them, she had a baby?" and you know, they're kind of going on and gossiping between themselves and my friend was sitting there listening, he could hear them talking about this, and he said he was two seconds away from turning around to say something to them, but one of them stopped and said, "well, I know, but I heard that the other one, she's a real hard worker.... and so, you know, I guess it's probably okay."

As Jill reflected on the story, she believed that the gossiping men had justified and made sense of what was, in two women living together and having a baby, a serious challenge to their norm by deciding that, "one's a hard worker. And she's farming. So I think it's okay." To prove themselves as farmers, participants sought out extensive professional development, attended local and national conferences, conducted grant-funded research on their farms, and consistently worked to improve their farming practices and expand their farms. Together, three lesbian farmers in Missouri founded the Missouri Young Farmers Collective, which provided monthly social events and farm tours for participating farmers and hosted a yearly educational workshop. While the genders or sexual orientations of the founders did not push the organization toward an explicitly queer mission, it is telling that through the organization, these women found ways to simultaneously build community and improve themselves as farmers.

\section{Conservative Surroundings}

Participants faced the twin challenges of attempting to advance small-scale, sustainable agriculture in the row crop-driven state of Missouri and attempting to live a full life as a lesbian in a conservative area. Discussions of these two forms of conservatism permeated the data collection. Conservatism as a concept, specifically a concept that set the participants apart from their surroundings and made them different in some way, emerged as religious and political conservatism, as well as a more conservative or conventional form of agriculture. Jill described the location of her farm as "the heart of the Republican Bible belt." Although farming and a shared commitment to the land helped Jill to build relationships with her conservative neighbors, there were still times when their differences were too deep to bridge. Jill spoke of a hurtful incident with close friends she had made in her community:

They're Pentecostal. They're hard core Christians. And when we [Jill and her now wife] had our commitment ceremony in 2010, the first year that I was farming, we sent them an invitation and they would not come. They're really religious, and he doesn't think it's right; he thinks that people that are lesbians or gay had to have been mistreated as children because that's the only explanation he can come up with in his mind of why somebody would be gay.

Finally, Jill reflected upon the agricultural conservatism in her area, stating, "I mean obviously I'm not selling my produce to the people that are out here in this community ... mostly I sell into an urban, liberal community, and if I didn't have that I would not be able to farm, for sure." Jill's certified organic, "FarmHer" grown produce was a hot commodity in the liberal college town 45 minutes from her farm, but to those in her immediate vicinity, she and her agricultural practices were quite anomalous. Laurie expanded on a similar notion of agricultural conservatism and how it contrasted her philosophy and methods of farming, stating:

What I guess I should say is that, row crop 
farming versus market farming, you could kind of categorize row crop farming as being more rural and conservative, kind of old school conservative, kind of good old boy type of conservative. Versus vegetable farming where you have a lot of young people who have never farmed before coming into this profession, and so you end up with, I think, a more liberal group of people in general who are growing vegetables over row crops.

Both participants discussed how having a more liberal market for their produce, and the more liberal, young agricultural community toward which they gravitated, made being a lesbian a non-issue in these circles, even though in the broader Missouri agricultural landscape they encountered prejudice.

\section{Discussion, Conclusions, and Implications}

Although instances of intolerance and bias existed, overall, the story of Missouri's lesbian farmers was one of empowerment and pride. Consistent with the literature, participants expressed fulfillment in being able to feed their communities and work collaboratively with nature, all while comfortably enacting a gender expression of female masculinity Jarosz, 2011; Kazyak, 2012; Rissing, 2013; Trauger, 2004). While the theme of "proving yourself" that emerged from the data was not explicitly expressed in prior literature, it was reminiscent of Kazyak's (2011) theme of "being a good person" (p. 571) in that it justified one's existence in and contribution to the rural space. The notion of “proving yourself" also intertwined with other scholarship on rural queer community-building (Bell \& Valentine, 1995; Leslie, 2017). Participants noted the abundance of fellow lesbians in sustainable agriculture, reflected on the value of lesbian mentorship in their personal and professional lives, and described the profession as a welcoming space for queer women.

The experiences of the women in the study track closely with the six themes outlined in FAST (Sachs et al., 2016), as they asserted the identity of farmer, integrated their economic, environmental, and social values into their farming practices, and negotiated their roles in agricultural institutions. The scholars who developed FAST acknowledged that it "is not a conclusion but rather a tool" offered to "better understand women in agriculture more thoroughly" (Sachs et al., 2016, p. 148). By attending to sexuality, and not just gender, I aimed to further this process of understanding the multifaceted, intersectional experiences of women farmers. Layering a marginalized sexual identity on top of a marginalized gender identity (in agriculture) requires us to complicate our perceptions of even seemingly inclusive, feminist worldviews, organizations, or social systems.

This study marks a contribution to the body of ecogender studies work in that it utilized the framework in a North American agricultural context, and it considered gender in intersection with sexuality (Banerjee \& Bell, 2007). Participants demonstrated a gendered and sexuality-influenced means of engaging with the environment and natural world through agriculture. Electronic artifact sources reflected this ecological commitment, illustrated by quotes such as "My goal is to give back more to the soil than I take," and "Our mission is to provide sustainably produced, high-quality foods to our community while improving the land and upholding our values of social and ecological justice." Additionally, participants embodied the emancipatory potential of engaging in meaningful, self-directed work in cooperation with nature (Salleh, 1984). Missouri's lesbian farmers seamlessly addressed the three legs of the stool of sustainability-economic, social, and ecological —in their discourse, and represent an important population to engage in advancing sustainable agriculture and building resilient food systems.

While many experiences of Missouri's lesbian farmers may be consistent with those of straight women farmers in Missouri, or with the experiences of women-identifying farmers throughout the United States, it is critical that researchers and practitioners attend to those that are different. In this case study, participants described several distinctively lesbian experiences that warrant further exploration. Lesbian mentorship and/or seeking out a lesbian-owned farm as a safe space to work was important to some participants, especially during their "coming out" process. Though participants generally felt more comfortable on womenowned farms than those owned by men, the addi- 
tional layer of safety they felt when the woman owner was a fellow lesbian differentiated the "lesbian experience" from the "woman experience." Critical distinctions between the experiences of women farmers and lesbian farmers also emerged in the example of Jill's close, conservative farmer friends refusing to attend her commitment ceremony, and in the gossip about her wife having a baby. While straight women farmers may also feel the need to prove their competence, in Jill's case, proving herself as a farmer meant justifying her right to be married and have children. If Jill were a straight woman, her human rights might not be so dependent on her work ethic.

I argue that Missouri's lesbian farmers have a unique set of experiences within the landscape of agriculture in the United States and that their perspectives provide valuable insight into addressing issues of sustainability. Small-scale, sustainable agriculture is a welcoming space for lesbian farmers without a farm background, and I encourage concerted recruitment efforts targeting these popula- tions. Additionally, I encourage conservation agents, extension professionals, and food systems practitioners to educate themselves about issues pertaining to rural queer livelihoods and to engage with and learn from lesbian farmer populations. As Leslie (2017) has argued and I reiterate, agriculture can only be ecologically and socially sustainable when the identities, perspectives, and epistemologies of queer people are fully embraced. Rural America faces ongoing, expansive population decline and economic depression, and the vitality of these communities hangs in the balance (Cromartie, 2017). The lesbian farmers whose stories contributed to this study represent a subset of the United States population who are eager to move to the country, care for its land and resources in sustainable ways, and contribute to communities and economies in rural locations. Future work should examine barriers to land access faced by lesbian farmers and should interrogate further questions of the emancipatory potential of agriculture for both farmers and nature.

\section{References}

Anahita, S. (2003). Landdyke landscapes: The politics, participants, and praxis of the lesbian land movement. (Doctoral dissertation). Retrieved from Iowa State University Digital Repository (AAI3085887). https://doi.org/10.31274/rtd-180813-12110

Anahita, S. (2009). Nestled into niches: Prefigurative communities on lesbian land. Journal of Homosexuality, 56(6), 719-737. https://doi.org/10.1080/00918360903054186

Banerjee, D., \& Bell, M. M. (2007). Ecogender: Locating gender in environmental social science. Society and Natural Resources, 20(1), 3-19. https://doi.org/10.1080/08941920600981272

Barlett, P. F., \& Conger, K. J. (2004). Three visions of masculine success on American farms. Men and Masculinities, 7(2), 205-227. https://doi.org/10.1177/1097184X03257409

Bell, D., \& Valentine, G. (1995). Queer country: Rural lesbian and gay lives. Journal of Rural Studies, 11(2), $113-122$. https://doi.org/10.1016/0743-0167(95)00013-D

Bowen, G. G. (2009). Document analysis as a qualitative research method. Qualitative Research Journal, 9(2), 27-40. https://doi.org/10.3316/QRJ0902027

Brandth, B. (1995). Rural masculinity in transition: Gender images in tractor advertisements. Journal of Rural Studies, 11(2), 123-133. https://doi.org/10.1016/0743-0167(95)00007-A

Browne, K. (2005). Snowball sampling: Using social networks to reach non-heterosexual women. International Journal of Social Research Methodology, 8(1), 47-60. https://doi.org/10.1080/1364557032000081663

CAFNR. (n.d.). College of Agriculture, Food, and Natural Resources: Research. Retrieved September 2, 2018, from https://cafnr.missouri.edu/research/

Corbin, J., \& Morse, J. M. (2003). The unstructured interactive interview: Issues of reciprocity and risks when dealing with sensitive topics. Qualitative Inquiry, 9(3), 335-354. https://doi.org/10.1177/1077800403009003001

Creswell, J. W. (2013). Qualitative inquiry and research design: Choosing among five approaches. Thousand Oaks, CA: Sage.

Creswell, J. W., \& Miller, D. L. (2000). Determining validity in qualitative inquiry. Theory into Practice, 39(3), $124-130$. https://doi.org/10.1207/s15430421tip3903 2 
Cromartie, J. (2017, September 5). Rural areas show overall population decline and shifting regional patterns of population change. USDA ERS Amber Waves. Retrieved from https://www.ers.usda.gov/amber-waves/2017/september/ruralareas-show-overall-population-decline-and-shifting-regional-patterns-of-population-change/

Fellows, W. (Ed.). (1998). Farm boys: Lives of gay men from the rural Midwest. Madison, WI: University of Wisconsin Press.

Ferrell, A. (2012). Doing masculinity: Gendered challenges to replacing burley tobacco in central Kentucky. Agriculture and Human V alues, 29(2), 137-149. https://doi.org/10.1007/s10460-011-9330-1

Gershuny, G. (1991). Women in alternative agriculture. Organic Farmer, 2(3), 5-21. https://organicfarmingmag.com

Gray, M. L., Johnson, C. R., \& Gilley, B. J. (Eds.). (2016). Queering the countryside: New frontiers in rural queer studies. New York: New York University Press.

Highfield, T., \& Leaver, T. (2015). A methodology for mapping Instagram hashtags. First Monday, 20(1), 1-11. https://firstmonday.org/ojs/index.php/fm/article/view/5563

Hochman, N., \& Manovich, L. (2013). Zooming into an Instagram City: Reading the local through social media. First Monday, 8(7). https://doi.org/10.5210/fm.v18i7.4711

Jackson, J. B. (1984). Discovering the vernacular landscape. New Haven, CT: Yale University Press.

Jarosz, L. (2011). Nourishing women: Toward a feminist political ecology of community supported agriculture in the United States. Gender, Place, \& Culture, 18(3), 307-326. https://doi.org/10.1080/0966369X.2011.565871

Kazyak, E. (2011). Disrupting cultural selves: Constructing gay and lesbian identities in rural locales. Qualitative Sociology, 34(4), 561-581. https://doi.org/10.1007/s11133-011-9205-1

Kazyak, E. (2012). Midwest or lesbian? Gender, rurality, and sexuality. Gender and Society, 26(6), 825-848. https://doi.org/10.1177/0891243212458361

Leslie, I. S. (2017). Queer farmers: Sexuality and the transition to sustainable agriculture. Rural Sociology, 82(4), 747-771. https://doi.org/10.1111/ruso.12153

Limbaugh, R. (2016, August 17). Latest lib assaults: Lesbian farmers, transgender homeless shelters, American flags ripped from fire trucks [Radio show episode]. In R. Limbaugh (Host), The Rush Limbaugh Show. Retrieved from https://www.rushlimbaugh.com/daily/2016/08/17/latest lib assaults lesbian farmers transgender homeless shelters american flags ripped from fire trucks/

Lincoln, Y. S., \& Guba, E. G. (1985). Naturalistic inquiry. Beverly Hills, CA: Sage. https://doi.org/10.1016/0147-1767(85)90062-8

Lesbian Natural Resources (LNR). (n.d.). Herstory and mission. Retrieved March 12, 2016, from http://www.lesbiannaturalresources.org/about/

Missouri Farm Bureau (MFB). (n.d.). About us. Retrieved June 15, 2018, and archived at https://web.archive.org/web/20151122001231/https://www.mofb.org/AboutUs.aspx

MFB. (2020). 2020 policy book. Retrieved from https://mofb.org/MOFB/wpcontent/uploads/2020/02/2020MOFBPolicyBook.pdf

Obergefell v. Hodges, 135 U. S. 2071 (2015).

Oswald, R. F., \& Culton, L. S. (2003). Under the rainbow: Rural gay life and its relevance for family providers. Family Relations, 52(1), 72-81. https://doi.org/10.1111/j.1741-3729.2003.00072.x

Peter, G., Bell, M. M., Jarganin, S., \& Bauer, D. (2000). Coming back across the fence: Masculinity and the transition to sustainable agriculture. Rural Sociology, 65(2), 215-233. https://doi.org/10.1111/j.1549-0831.2000.tb00026.x

Rissing, A. L. (2013). Iowan women farmers' perspectives on alternative agriculture and gender. Journal of Agriculture, Food Systems, and Community Development, 3(2), 127-136. https://doi.org/10.5304/jafscd.2013.032.008

Rust, N. A., Abrams, A, Challender, D. W., Chapron, G., Ghoddousi, A., Gilkman, J. A., .. Sutton, A. (2017). Quantity does not always mean quality: The importance of qualitative social science in conservation research. Society and Natural Resources, 30(10), 1304-1310. https://doi.org/10.1080/08941920.2017.1333661

Sachs, C. E. (1983). The invisible farmers: Women in agricultural production. Totowa, NJ: Rowman and Allanheld.

Sachs, C. E. (1992). Reconsidering diversity in agriculture and food systems: An ecofeminist approach. Agriculture and Human Values, 9(3), 4-10. https://doi.org/10.1007/BF02217916 
Sachs, C. E. (1996). Gendered fields: Rural women, agriculture, and environment. Boulder, CO: Westview Press. https://doi.org/10.1007/978-1-349-24611-3 21

Sachs, C. E., Barbercheck, M. E., Brasier, K. J., Kiernan, N. E., \& Terman, A. R. (2016). The rise of women farmers and sustainable agriculture. Iowa City: University of Iowa Press. https://doi.org/10.2307/j.ctt20p57gr

Salleh, A. (1984). Deeper than deep ecology: The ecofeminist connection. Environmental Ethics, 6(4), 339-345. https://doi.org/10.5840/enviroethics1984645

Stake, R. E. (1995). The art of case study research. Thousand Oaks, CA: Sage.

Taylor, Y., Hines, S., \& Casey, M. (2010). Theorizing intersectionality and sexuality. Basingstoke, UK: Palgrave Macmillan. https://doi.org/10.1057/9780230304093

Trauger, A. (2004). 'Because they can do the work': Women farmers in sustainable agriculture in Pennsylvania, USA. Gender, Place, and Culture, 11(2), 289-307. https://doi.org/10.1080/0966369042000218491

U.S. Department of Commerce (USDC). (2012). Missouri: 2010: Population and housing unit counts. Retrieved from https://www.census.gov/prod/cen2010/cph-2-27.pdf

U.S. Department of Agriculture (USDA). (2014a). Census of agriculture: 2012 Census volume 1, chapter 1: U.S. National Level Data. Retrieved from https://www.nass.usda.gov/Publications/AgCensus/2012/Full Report/Volume 1, Chapter 1 US/

USDA National Agricultural Statistics Service (NASS). (2014b). 2012 Census of Agriculture: Characteristics of all farms and farms with organic sales. Washington, DC: USDA. Retrieved from https://www.nass.usda.gov/Publications/AgCensus/2012/Online Resources/Special Organics Tabulation/organ ictab.pdf

USDA National Agricultural Statistics Service (NASS). (2018). State Fact Sheets: Missouri. Retrieved from https://data.ers.usda.gov/reports.aspx?StateFIPS=29\&StateName=Missouri\&ID=17854

Warren, K. J. (1996). Ecological feminist philosophies: An overview of the issues. Bloomington, IN: Indiana University Press.

Wypler, J. (2019). Lesbian and queer sustainable farmer networks in the Midwest. Society \& Natural Resources, 32(8), 947-964. https://doi.org/10.1080/08941920.2019.1584834

Yin, R. K. (2003). Case study research: Design and methods. Thousand Oaks, CA: Sage. 